\title{
ИЗМЕНЕНИЕ ЭЛЕМЕНТНОГО СОСТАВА ВЕРХНЕГО ГОРИЗОНТА ПОЧВ ПОД ВОЗДЕЙСТВИЕМ ПРЕДПРИЯТИЙ НЕФТЕГАЗОПЕРЕРАБОТКИ
}

\author{
Боев Владислав Викторович',
}

v.-3@mail.ru

Барановская Наталья Владимировна', natalya.baranovs@mail.ru

Боев Виктор Александрович², vikboev2009@mail.ru

\section{Джамбаев Мерей Тлеуканович1,3,}

merei-semei@mail.ru

\author{
Шахова Татьяна Сергеевна', \\ tatyanags29@yandex.ru
}

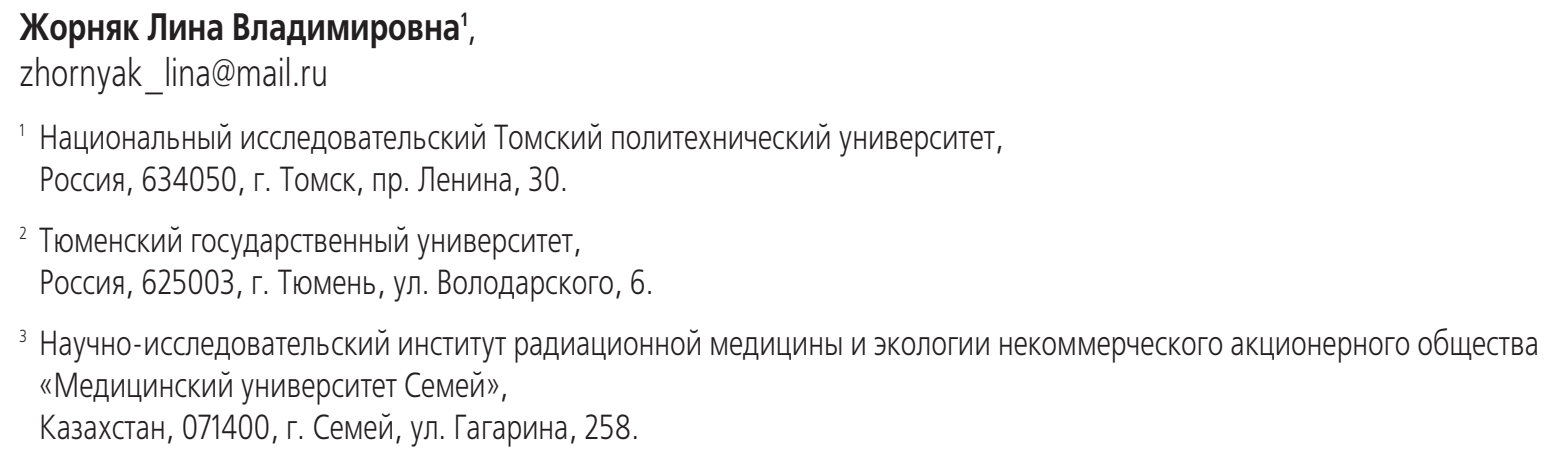

Актуальность исследования обусловлена отсутствием данных по воздействию многих нефтеперерабатывающих заводов и прочих техногенных объектов на прилегающие почвы для конкретных регионов при изученности общей геохимической специфики промышленных отраслей

Цель исследования состоит в выявлении специфики воздействия нефтеперерабатывающих заводов и некоторых прочих техногенных объектов на почвы путем сопоставления элементного состава с данными условно-фоновой территории и кларком.

Объекты: почвы Тюменского федерального заказника и территорий расположения Антипинского, Омского, Ачинского, Павлодарского нефтеперерабатывающих заводов, почвы населенных пунктов Томской области и г. Томска, почвы территории, подверженной воздействию бывшего Семипалатинского испытательного полигона.

Методы: выбор и подготовка пробных площадок, отбор и подготовка почв, определение элементного состава инструментальным нейтронно-активационным и атомно-абсорбционным методами, интерпретация результатов

Результаты. Исследован элементный состав верхнего горизонта почв восточной части Тюменского федерального заказника, территории расположения Антипинского, Омского, Ачинского, Павлодарского нефтеперерабатывающих заводов, районов расположение предприятий г. Томска, зоны влияния бывшего Семипалатинского испытательного полигона. В результате сравнения с данными для региональных почв выявлена геохимическая специфика каждого техногенного района. Отражено отличие в элементном составе почв, прилегающих к разным нефтеперерабатывающим заводам, что определяется как техническими параметрами самих предприятий, так и экологическими условиями территорий их расположения. Путем сопоставления с кларком и условно-фоновой территорией установлен уровень загрязнения и спектр химических элементов, характеризующихся повышенным содержанием, для названных территорий. На примере Антипинского нефтеперерабатывающего завода изучено пространственное распределение элементов по удаленности и сторонам света от техногенного объекта.

\section{Ключевые слова:}

Элементный состав почв, Тюменский федеральный заказник, Антипинский НПЗ,

техногенное воздействие на почвы, почвы г. Томска, Павлодарский НПЗ, почвы Томской области,

Ачинский НПЗ, территория влияния бывшего Семипалатинского испытательного полигона, Омский НПЗ.

\section{Введение}

Изменение процессов миграции и накопления химических элементов в различных природных средах под влиянием техногенных процессов как на глобальном, так и на локальном уровнях изучают с момента введения термина «техногенез» [1].
За это время накоплено много данных по миграции химических элементов в компонентах биогеоценозов и изменениям природных сред в условиях техногенеза [2-10]. Однако весьма актуальны в настоящее время вопросы выбора условного фона и установления особенностей распределения химических элементов, а также их совокупного эффек- 
та на локальных территориях, подверженных специфическому антропогенному влиянию.

Месторождения углеводородного сырья открыты в 90 странах. $K$ данному моменту переработано более 90 млрд т нефти. К 2001 г., по данным Oil\&Gas Journal, по миру функционировало 742 нефтеперерабатывающих завода (НПЗ). Их общая мощность составляла 4,07749 трлн т нефти в год либо 81,25159 млн баррелей в сутки. Средняя мощность НПЗ - 5,48 млн т в год. При этом использование углеводородного сырья все возрастает, особенно в развитых странах. Так, количество использованного за последние 25-30 лет топливно-энергетических ресурсов равно количеству, потраченному за всю прошедшую историю человечества. $3 / 4$ из него составляют нефть и газ.

Функционирование нефтедобывающей и нефтеперерабатывающей промышленности сопровождается утечками нефти, сжиганием попутных газов, влиянием изливаемых нефтяных вод и хранением шламов [11]. Таким образом, данные объекты оказывают воздействия различного рода на компоненты природной среды [12 и др.] и здоровье людей [13-18 и др.].

Большинство исследований влияния нефтедобывающей и нефтеперерабатывающей промышленности на природную среду сосредоточено на углеводородах как основных загрязнителях данной отрасли и некоторых прочих химических соединениях [19-23 и др.]. Однако помимо них НПЗ поставляют в окружающую среду и многие прочие вещества, специфическими среди которых являются: $\mathrm{Br}, \mathrm{Sb}$,

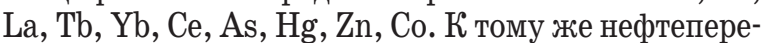
рабатывающие заводы различаются составом выбросов и их распространением [24-26 и др.]. Известны общие факторы, определяющие этот состав для промышленных объектов [27]. Эти факторы индивидуальны для каждого предприятия и района: технические параметры, особенности места расположения (рельеф, преимущественное направление ветра и т. д.). НПЗ характеризуются наличием множества источников выбросов с различными параметрами [28] и их сложным составом, характеризующимся выявленными специфическими элементами [29], концентрирующимися в различных компонентах природной среды.

В результате их разноса загрязнение распространяется от техногенных объектов в виде ореолов, форма и размер которого определяются параметрами предприятия, а также природными факторами, прежде всего, преимущественными направлениями ветра [27]. Также на степень загрязнения атмосферы влияет мощность НПЗ, особенности технологических схем, арматуры, проектных решений, техническое состояние оборудования и коммуникаций.

Ввиду этого актуально более обширное поэлементное исследование выбросов НПЗ и экологического воздействия каждого из них.

K тому же важны пространственные закономерности распространения выбросов от объекта.
Изучение влияния нефтеперерабатывающей промышленности на природные среды и объекты является важной геоэкологической задачей. Очень большую долю испускаемых загрязняющих веществ нефтеперерабатывающей промышленности составляют атмосферные выбросы. По загрязнению атмосферы нефтеперерабатывающая и нефтехимическая промышленность находятся на 4 месте среди прочих отраслей [28]. Причем местными НПЗ выбрасывается в атмосферу 0,45 \% перерабатываемого сырья в сравнении с 0,1\% западных НПЗ. Наибольшее воздействие оказывается на среды, непосредственно контактирующие с атмосферой: растительность и почву. Каждый из данных природных компонентов имеет определенные индикаторные параметры. Значение изучения почвы определяется следующими факторами. Во-первых, существенная часть выбросов НПЗ попадает в почву. Во-вторых, оттуда загрязнители распространяются по наземным живым организмам, прежде всего растениям. Существенное значение в геоэкологических исследованиях имеют особенности компонентов природной среды, называемые индикаторными параметрами. В контексте исследований элементного состава они состоят в различных параметрах накопления разных химических элементов. Таким образом, каждый компонент природной среды отражает специфические параметры техногенного воздействия [30, 31].

Геоэкологические исследования, направленные на выявление техногенного воздействия, осуществляют путем сопоставления показателей техногенных территорий с какими-либо значениями, принятыми за естественные. Они могут быть представлены средними показателями содержания химических элементов в каком-либо компоненте природной среды, называемыми кларками, либо аналогичными значениями для конкретного региона. Подход с применением региональных данных считают более корректным. Это объясняется тем, что каждый регион характеризуется конкретной геохимической спецификой, которая может значительно отличаться от общей. Таким образом для корректного выявления техногенного воздействия на природные компоненты следует использовать с целью сопоставления местный фон. Изучение в совокупности с этим воздействия предприятий ведущей региональной отрасли промышленности позволяет выявить экологическую специфику. Однако во многих случаях возникает проблема поиска фоновой территории, учитывая современные масштабы техногенеза и урбанизации. Наиболее подходящими объектами с данной точки зрения считают особо охраняемые территории, где не ведется хозяйственная и промышленная деятельность.

\section{Материалы и методы}

В данной работе было проведено сравнение почв территории Тюменского федерального заказника в качестве условно-фоновых и почв вблизи 
Антипинского нефтеперерабатывающего завода.

В фоновых условиях отбор почв производился с предварительно созданной площадки на территории Тюменского федерального заказника у его восточной границы, вблизи поселка Бухтал, общей площадью 0,25 га в соответствии с [32]. На техногенной территории отбор проб почвы вблизи Антипинского НПЗ, находящегося на юго-восточной окраине г. Тюмени и функционирующего с 2006 г., производился в соответствии с [33] по системе концентрических окружностей. Помимо этого, три разреза размещены на территории, наименее затронутой урбанизацией и близкой по ландшафту к условно-фоновой. Территория отбора радиусом чуть более 2 км от НПЗ была произвольно подразделена на 3 зоны $(420-490,700-1130$, $1300-2170 \mathrm{~m})$.

Кроме того, с целью проведения сравнительного анализа и выявления специфики предприятий нефтепереработки нами были отобраны пробы в районе деятельности Омского (функционирует с 1955 г.), Ачинского (с 1982 г.), Павлодарского (с 1978 г.) НПЗ. Проведен также сравнительный анализ с почвами территории, характеризующейся комплексным техногенезом (г. Томск), а также ядерным техногенезом (бывший Семипалатинский испытательный полигон (СИП)). В качестве условно-фоновых были использованы почвы Тюменского федерального заказника (ТФЗ).

Тюмень расположена в зоне умеренно-континентального климата. В изученных районах преобладают смешанные, хвойные и лиственные леса, почвы - дерново-подзолистые, урбаноземы. Томская область находится в условиях континентально-циклонического климата. Преобладают леса (хвойные, смешанные, широколиственные) и лесостепи, почвы - подзолистые, дерново-подзолистые, серые лесные, черноземы, пойменные, болотные, урбаноземы. Для Омска характерен резкоконтинентальный климат. Из ландшафтов преобладают лесостепи и степи. Почвы в районе НПЗ представлены серыми лесными, выщелоченными черноземами, луговыми, черноземно-луговыми, солонцами. Ачинск находится в зоне резко-континентального климата в зоне лесостепей и гористой местности, покрытой хвойными, лиственными и смешанными лесами. Почвы - серые лесные, темно-серые, черноземы. Для Павлодара характерен резко-континентальный климат. Около города преобладают луга, степи и хвойные леса, почвы темно-каштановые. Восточно-Казахстанская область (ВКО) характеризуется резко-континентальным климатом. В рассматриваемом районе области преобладают степи и хвойные леса, почвы - боровых песков, каштановые, низкогорные, солонцы.

Общее количество проб почвы составило 393 , включая 5 для ТФЗ, 23 для Антипинского НПЗ, 24 для Омского, 25 для Ачинского, 10 для Павлодарского, 61 для г. Томска, 192 для Томской области, 53 для бывшего СИП.
Отбор почв на территории Тюменской области производился из разрезов в соответствии с рекомендациями Б.Г. Розанова, Г.С. и А.Г. Фоминых и методами изучения лесных сообществ [34, 35]. На основных точках данной урбанизированной территории вместо разрезов использовались прикопки для отбора верхнего горизонта почвы в соответствии с рекомендациями Г.С. и А.Г. Фоминых [35].

Ландшафт условно-фоновой территории Тюменского федерального заказника представлен березово-сосновым с липой лесом. Техногенная территория представлена окрестностями Антипинского НПЗ (природно-техногенная территория радиусом около 2 км от объекта) с различной степенью техногенного преобразования. Наиболее затронута территория к северу от завода, представленная урбанизированным районом в виде поселка Антипино до берега реки Тура. В южном направлении находится наименее затронутая техногенезом территория, представленная лиственными, хвойными и смешанными участками леса с небольшим количеством техногенных объектов. На востоке и западе находятся урбанизированные территории с небольшими участками лиственного леса. Согласно классификации СССР, почвы условно-фоновой территории представлены дерново-подзолистым типом [36], материнские породыпесчано-аллювиальными отложениями, о чем свидетельствует преобладание легких и средних суглинков. Почвы техногенной территории представлены дерново-подзолистыми и урбоземами в зависимости от техногенной измененности территории. Подстилающие породы на исследуемом участке условно-фоновой территории представлены верхнеолигоценовыми алевритами и алевристыми глинами туртасской свиты с линзами тонкозернистых песков, на техногенной территории - среднеи верхнеэоценовыми алевристыми зеленоцветными глинами тавдинской свиты с присыпками и гнездами песков и алевритов, прослоями кварцево-глауконитовых песков и включениями глинистых сидеритов, и сменяющими их к югу нижнеолигоценовыми песками куртамышской свиты с прослоями глин, алевритов, с линзами лигнита и включениями растительных остатков [37].

Содержание химических элементов в почвах было определено инструментальным нейтронноактивационным анализом в ядерно-геохимической лаборатории ТПУ. Измерение осуществлялось на многоканальном анализаторе импульсов AMA $02 \Phi$ с полупроводниковым Ge-Li детектором ДГДК-63А. Плотность потока тепловых нейтронов в канале облучения составляла $2 \cdot 10^{13}$ нейтр. $/ \mathrm{cm}^{2} \cdot$. Продолжительность облучения проб - до 20 часов. В качестве стандартного образца использовался БИЛ-1 [38]. Измерение содержания ртути осуществлялось на РА-915+ с приставкой РП-91C с использованием пакета РП-91С (стандартный образец - ГСО-290).

Для получения статистических показателей использовался пакет анализа Statistika 6.0. Срав- 
Известия Томского политехнического университета. Инжиниринг георесурсов. 2019. Т. 330. № 11. 179-191

Боев В.В. и др. Изменение элементного состава верхнего горизонта почв под воздействием предприятий ...

Таблица 1. Содержание химических элементов в верхнем горизонте почв территорий с различной техногенной нагрузкой

Table 1. Content of chemical elements in the upper horizon of the soils of territories with different anthropogenic load

\begin{tabular}{|c|c|c|c|c|c|c|c|c|}
\hline \multirow[b]{2}{*}{ 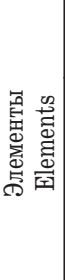 } & \multicolumn{2}{|c|}{$\begin{array}{c}\text { Среднее для населенных пунктов } \\
\text { Average for settlements }\end{array}$} & \multicolumn{2}{|c|}{$\begin{array}{l}\text { Тюменская область } \\
\text { Tyumen region }\end{array}$} & \multicolumn{2}{|r|}{$\begin{array}{l}\text { Томская область } \\
\text { Tomsk region }\end{array}$} & \multicolumn{2}{|c|}{$\begin{array}{c}\text { ВК0 } \\
\text { East Kazakhstan Region }\end{array}$} \\
\hline & \begin{tabular}{|c|} 
Хутора, малые \\
поселки, \\
станицы \\
Farms, small \\
villages, \\
stanitsy [40]
\end{tabular} & $\begin{array}{c}\text { Города } \\
>700 \text { тыс. чел. } \\
\text { Cities }>700 \text { thou- } \\
\text { sands people [40] }\end{array}$ & $\begin{array}{c}\text { Тюменский } \\
\text { федеральный } \\
\text { заказник } \\
\text { Tyumen } \\
\text { Federal Reserve }\end{array}$ & $\begin{array}{c}\text { г. Тюмень } \\
\text { Туumen } \\
{[41,42]}\end{array}$ & $\begin{array}{c}\text { Населенные } \\
\text { пункты Том- } \\
\text { ской области } \\
\text { Settlements } \\
\text { of the Tomsk } \\
\text { region }\end{array}$ & $\begin{array}{c}\text { Районы расположения про- } \\
\text { мышленных предприятий } \\
\text { г. Tомска (среднеe) } \\
\text { Location of industrial } \\
\text { enterprises of Tomsk } \\
\text { (average) }\end{array}$ & \begin{tabular}{|l} 
Район \\
c. Сосновка \\
[43] \\
District \\
Sosnovka
\end{tabular} & $\begin{array}{c}\text { Территории, } \\
\text { прилегающие к } \\
\text { бывшему СИП } \\
\text { Territories } \\
\text { adjacent to the } \\
\text { former STS }\end{array}$ \\
\hline $\mathrm{Na}$ & - & 6600 & 4621 & - & 8700 & - & - & $15549 \pm 352$ \\
\hline $\mathrm{Ca}$ & - & 17100 & 8052 & - & 20760 & 16000 & - & $20686 \pm 1514$ \\
\hline Sc & 6 & 8,6 & 2,5 & - & 8,7 & 10,9 & - & $11 \pm 0,5$ \\
\hline $\mathrm{Cr}$ & 53 & 83 & 134 & $94(61 \pm 18)$ & 119 & 128 & 20 & $75 \pm 2,9$ \\
\hline $\mathrm{Fe}$ & - & 19600 & 6008 & - & 23002 & 29500 & - & $31104 \pm 1216$ \\
\hline $\mathrm{Co}$ & 11 & 16 & 5 & $17(56 \pm 17)$ & 12 & 17 & 4,2 & $12 \pm 0,8$ \\
\hline $\mathrm{Zn}$ & 98 & 201 & 16 & $64(64 \pm 19)$ & - & 182 & 52 & $205 \pm 12$ \\
\hline As & 22 & 25 & 1,4 & - & 4,5 & 14 & - & $5,7 \pm 0,3$ \\
\hline $\mathrm{Br}$ & - & - & 0,84 & - & 19 & 10 & - & $13 \pm 1,2$ \\
\hline $\mathrm{Rb}$ & - & 58 & 30 & - & 77 & 72 & - & $67 \pm 5,1$ \\
\hline $\mathrm{Sr}$ & 232 & 358 & 66 & 183 & 210 & НПО $>50 \%$ & 122 & $159 \pm 19$ \\
\hline $\mathrm{Ag}$ & - & 0,4 & - & - & 1,9 & - & - & $<1$ \\
\hline $\mathrm{Sb}$ & - & - & 0,26 & - & 1,2 & 3,6 & - & $1 \pm 0,1$ \\
\hline $\mathrm{Cs}$ & - & - & 0,61 & - & 3,1 & 3,3 & - & $2,8 \pm 0,2$ \\
\hline $\mathrm{Ba}$ & 537 & 881 & 289 & - & 501 & 423 & - & $437 \pm 16$ \\
\hline $\mathrm{La}$ & - & 15 & 8 & - & 23 & 26 & - & $23 \pm 0,7$ \\
\hline $\mathrm{Ce}$ & - & - & 20 & - & 45 & 56 & - & $50 \pm 2$ \\
\hline $\mathrm{Nd}$ & - & - & 7 & - & - & - & - & $16 \pm 1,5$ \\
\hline $\mathrm{Sm}$ & - & - & 1,3 & - & 4,8 & 5,2 & - & $4,54 \pm 0,2$ \\
\hline $\mathrm{Eu}$ & - & - & 0,25 & - & 0,84 & 1,2 & - & $0,9 \pm 0,1$ \\
\hline $\mathrm{Tb}$ & - & - & 0,23 & - & 0,68 & 0,99 & - & $0,6 \pm 0,05$ \\
\hline $\mathrm{Yb}$ & 2,7 & 2,5 & 1,3 & - & 2,3 & 2,7 & - & $2,5 \pm 0,08$ \\
\hline $\mathrm{Lu}$ & - & - & 0,11 & - & 0,4 & 0,39 & - & $0,4 \pm 0,01$ \\
\hline Hf & - & - & 5,8 & - & 5,5 & 6,2 & - & $5,2 \pm 0,2$ \\
\hline $\mathrm{Ta}$ & 1 & 1 & 0,38 & - & 0,9 & 1,1 & - & $0,7 \pm 0,07$ \\
\hline $\mathrm{Au}$ & - & - & НПО $>50 \%$ & - & 0,03 & 0,014 & - & $0,01 \pm 0,003$ \\
\hline $\mathrm{Hg}$ & - & - & 0,026 & $(0,11 \pm 0,051)$ & & - & - & \\
\hline Th & - & - & 2,5 & - & 2,7 & 7,1 & - & $6,8 \pm 0,3$ \\
\hline $\mathrm{U}$ & - & - & 0,77 & - & 2,3 & 2,1 & - & $2,6 \pm 0,1$ \\
\hline
\end{tabular}

нительный анализ проводился с применением коэффициента ранговой корреляции Спирмена $(\mathrm{p}<0,5)$. Для характеристики специфики формирования геохимического фона использовался коэффициент концентрации химических элементов $(К \kappa)$, равный отношению его содержания в данной среде к фоновому. Для оценки степени загрязнения применяли суммарный показатель загрязнения $\left(\mathrm{Z}_{\mathrm{c}}\right)$, равный разности суммы коэффициентов концентрации химических элементов больше единицы и суммы количества этих элементов без одного из них, с дифференциацией значений [39].

\section{Результаты исследования и обсуждение}

Результаты сравнения данных районов с разной техногенной нагрузкй ярко демонстрируют влияние урбанизированных территорий с различными источниками техногенного воздействия на специфическое концентрирование элементов в верхнем горизонте почв. Данная закономерность более высоких концентраций специфических химических элементов для урбанизированных зон отмечена в работе [40].
Согласно этим данным, для почв крупных городов, в сравнении с селами и поселками, характерно повышенное накопление большинства химических элементов, за исключением $\mathrm{Yb}$ и Та. Нами для г. Тюмени отмечено повышенное содержание $\mathrm{Co}, \mathrm{Zn}, \mathrm{Sr}$, $\mathrm{Hg}$, но пониженное $\mathrm{Cr}$. Для урбаноземов г. Томска отмечено более высокое концентрирование $\mathrm{Sc}, \mathrm{Cr}$, $\mathrm{Fe}, \mathrm{Co}, \mathrm{As}, \mathrm{Sb}, \mathrm{Cs}, \mathrm{La}, \mathrm{Ce}, \mathrm{Sm}, \mathrm{Eu}, \mathrm{Tb}, \mathrm{Yb}, \mathrm{Hf}, \mathrm{Ta}$, Th и пониженное содержание $\mathrm{Ca}, \mathrm{Br}, \mathrm{Rb}, \mathrm{Ba}, \mathrm{Lu}, \mathrm{Au}, \mathrm{U}$ относительно населенных пунктов области. Для зоны влияния бывшего Семипалатинского испытательного полигона отмечается повышенное накопление $\mathrm{Cr}$, $\mathrm{Co}, \mathrm{Zn}, \mathrm{Sr}$ в сравнении с условно-фоновой территорией Восточно-Казахстанской области.

При сопоставлении результатов для почв Тюменской области с данными для Томска и Томской области выявлено значительно меньшее содержание большинства рассмотренных химических элементов. $\mathrm{K}$ исключениям относятся $\mathrm{Cr}$ и отчасти Hf и Th (табл. 1).

В целом следует отметить тот факт, что независимо от региона и типов почв наблюдается влияние 
процессов техногенеза на формирование геохимической специализации. В то же время существенным является вопрос специфики предприятий каждой территории и ее отражения в составе почвенного покрова. Так, для территории Западной Сибири отмечено специализированное накопление сурьмы, брома и ряда других элементов на территориях нефтегазодобычи и переработки [29]. Этот геохимический спектр ярко отличается от такового, сформировавшегося в районах воздействия предприятий энергетического или ядерно-топливного цикла.

Таблица 2. Содержание химических элементов в верхнем гори зонте почв территорий, подверженных воздействию НПЗ

Table 2. Content of chemical elements in the upper horizon of the soil of areas exposed to refineries

\begin{tabular}{|c|c|c|c|c|}
\hline \multirow{2}{*}{ 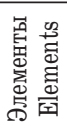 } & \multicolumn{4}{|c|}{$\begin{array}{l}\text { Территории, прилегающие к НПЗ } \\
\text { Territories adjacent to oil refinery }\end{array}$} \\
\hline & $\begin{array}{l}\text { Антипинскому } \\
\text { Antipinsky }\end{array}$ & $\begin{array}{l}\text { Омскому } \\
\text { Omsk }\end{array}$ & $\begin{array}{l}\text { Ачинскому } \\
\text { Achinsk }\end{array}$ & $\begin{array}{l}\text { Павлодарскому } \\
\text { Pavlodar }\end{array}$ \\
\hline $\mathrm{Na}$ & $7205 \pm 189$ & $8800 \pm 200$ & $8900 \pm 300$ & $15300 \pm 400$ \\
\hline $\mathrm{Ca}$ & $9189 \pm 443$ & $15000 \pm 1100$ & $16500 \pm 700$ & $14200 \pm 1300$ \\
\hline Sc & $3,5 \pm 0,34$ & $8,8 \pm 0,45$ & $13 \pm 0,31$ & $7,5 \pm 0,7$ \\
\hline $\mathrm{Cr}$ & $116 \pm 11$ & $169 \pm 48$ & $109 \pm 4,61$ & $60 \pm 6,11$ \\
\hline $\mathrm{Fe}$ & $9255 \pm 920$ & $23800 \pm 1200$ & $36200 \pm 900$ & $22500 \pm 1700$ \\
\hline $\mathrm{Co}_{0}$ & $7,1 \pm 1,2$ & $13 \pm 0,5$ & $18 \pm 0,56$ & $8,3 \pm 0,7$ \\
\hline $\mathrm{Zn}$ & $18 \pm 6$ & $81 \pm 18,7$ & $88 \pm 3,44$ & $49 \pm 5,42$ \\
\hline As & $1,5 \pm 0,14$ & $5,5 \pm 0,26$ & $7 \pm 0,4$ & $5,6 \pm 0,41$ \\
\hline $\mathrm{Br}$ & $1,5 \pm 0,37$ & $18 \pm 1,9$ & $34 \pm 3,1$ & $1 \pm 0,72$ \\
\hline $\mathrm{Rb}$ & $36 \pm 2,5$ & $79 \pm 2,7$ & $97 \pm 2,2$ & $77 \pm 4,29$ \\
\hline $\mathrm{Sr}$ & НПО $>50$ & $73 \pm 12,4$ & $105 \pm 17,2$ & $182 \pm 34$ \\
\hline $\mathrm{Sb}$ & $0,4 \pm 0,069$ & $0,76 \pm 0,05$ & $0,84 \pm 0,04$ & $0,79 \pm 0,06$ \\
\hline $\mathrm{Cs}$ & $0,86 \pm 0,094$ & $3,4 \pm 0,16$ & $4,6 \pm 0,16$ & $2,8 \pm 0,4$ \\
\hline $\mathrm{Ba}$ & $287 \pm 10$ & $377 \pm 10,2$ & $478 \pm 14$ & $398 \pm 11$ \\
\hline $\mathrm{La}$ & $9,5 \pm 0,74$ & $22 \pm 0,7$ & $31 \pm 0,7$ & $20 \pm 1,6$ \\
\hline $\mathrm{Ce}$ & $26 \pm 1,9$ & $51 \pm 1,5$ & $66 \pm 1,36$ & $42 \pm 2,61$ \\
\hline $\mathrm{Nd}$ & $4,6 \pm 0,8$ & $18 \pm 0,9$ & $23 \pm 0,9$ & $15 \pm 0,9$ \\
\hline $\mathrm{Sm}$ & $1,9 \pm 0,13$ & $4,1 \pm 0,12$ & $5,5 \pm 0,12$ & $3,7 \pm 0,23$ \\
\hline $\mathrm{Eu}$ & $0,48 \pm 0,036$ & $0,83 \pm 0,04$ & $1,3 \pm 0,03$ & $0,72 \pm 0,05$ \\
\hline $\mathrm{Tb}$ & $0,29 \pm 0,026$ & $0,6 \pm 0,03$ & $0,91 \pm 0,04$ & $0,59 \pm 0,05$ \\
\hline $\mathrm{Yb}$ & $1 \pm 0,066$ & $2,1 \pm 0,07$ & $2,9 \pm 0,06$ & $2,1 \pm 0,14$ \\
\hline $\mathrm{Lu}$ & $0,13 \pm 0,011$ & $0,31 \pm 0,01$ & $0,42 \pm 0,01$ & $0,28 \pm 0,02$ \\
\hline $\mathrm{Hf}$ & $5,7 \pm 0,41$ & $6,2 \pm 0,26$ & $6,3 \pm 0,2$ & $4,2 \pm 0,41$ \\
\hline $\mathrm{Ta}$ & $0,35 \pm 0,059$ & $0,65 \pm 0,05$ & $0,92 \pm 0,05$ & $0,56 \pm 0,05$ \\
\hline $\mathrm{Au}$ & НПО $>50$ & $0,01 \pm 0,001$ & $0,01 \pm 0,008$ & $0,01 \pm 0,001$ \\
\hline $\mathrm{Hg}$ & $0,028 \pm 0,0041$ & $0,09 \pm 0,02$ & $0,03 \pm 0,01$ & $0,2 \pm 0,05$ \\
\hline Th & $3 \pm 0,25$ & $6,9 \pm 0,3$ & $8,9 \pm 0,3$ & $5,8 \pm 0,46$ \\
\hline $\mathrm{U}$ & $0,62 \pm 0,05$ & $1,9 \pm 0,12$ & $2,6 \pm 0,13$ & $2,1 \pm 0,14$ \\
\hline
\end{tabular}

Наши исследования по содержанию химических элементов в почвах района расположения $\mathrm{Aн}^{-}$ типинского нефтеперерабатывающего предприятия свидетельствуют о том, что имеет место специфика накопления, не только отличная от приведенного по Западной Сибири комплекса элементов, но и характеризующая каждое отдельное предприятие. Геохимические показатели формируются в зависимости от длительности работы предприятия, применения технологических схем, а также влияния различных типов катализаторов, часто используемых на таких объектах. В сравнении с почвами территорий расположения некото- рых других НПЗ содержание большинства химических элементов в почве района Антипинского НПЗ значительно ниже (табл. 2). Исключение составляют $\mathrm{Cr}$ и $\mathrm{Hf}$.

Наименьшая загрязненность почв территории Антипинского НПЗ в сравнении с используемыми данными подтверждается при сопоставлении значений содержания химических элементов с кларком [44] (табл. 3). Так, в данном случае наблюдаются повышенные коэффициенты концентрации лишь для $\mathrm{Na}$ и $\mathrm{Cr}$, а показатель суммарного загрязнения равен 1. Наибольший суммарный показатель загрязнения имеет территория г. Томска (средний уровень), для которой характерно комплексное техногенное воздействие. На втором месте находится территория, подверженная воздействию бывшего СИП (низкий уровень). При этом для двух данных объектов близки спектры химических элементов с повышенными коэффициентами концентрации. Следует отметить, что только на этих территориях встречаются высокие концентрации $\mathrm{Au}$ и Lu. Также весьма значительным спектром элементов с повышенным содержанием характеризуется территория, прилегающая к Ачинскому НПЗ, при суммарном показателе загрязнения, характеризующемся, согласно [39], как низкий.

Среди рассмотренных территорий расположения НПЗ наибольшим загрязнением по отношению к кларку, как по количеству химических элементов с повышенными коэффициентами концентрации, так и по суммарному показателю загрязнения, соответствующему низкому уровню загрязнения, характеризуются почвы территории расположения Ачинского НПЗ. При этом по показателю суммарного загрязнения остальные рассмотренные районы, подверженные влиянию нефтеперерабатывающих предприятий, характеризуются отсутствием загрязнения. Почвы, прилегающие к бывшему СИП, при том же количестве химических элементов с повышенными коэффициентами концентрации, что и почвы возле Омского НПЗ, имеют средний уровень загрязнения. Наибольший суммарный показатель загрязнения, соответствующий среднему уровню, имеют почвы г. Томска. Близкий уровень загрязнения почв территорий расположения предприятий г. Томска и прилегающих к бывшему СИП и сходный спектр элементов с повышенными коэффициентами концентрации, предположительно, связаны с аналогичным характером техногенной нагрузки, оказываемой предприятиями ядерно-топливного цикла.

Кроме того, изученные территории, подверженные техногенному воздействию, были нормированы относительно условного фона (табл. 4). Ввиду того, что данная территория характеризуется меньшими значениями содержания химических элементов в сравнении с кларком, для изученных данных всех районов большинство химических элементов имеют повышенные коэффициенты концентрации. 
Таблииа 3. Геохимический ряд и сулмарный показатель загряз нения для верхнего горизонта почв территорий, под верженных воздействию факторов техногенеза, от носительно кларка [44]

Table 3. Geochemical series and the total pollution indicator for the upper soil horizon of territories subject to the influence of factors of technogenesis, relative to the clarke

\begin{tabular}{|c|c|c|c|}
\hline \multirow{5}{*}{ 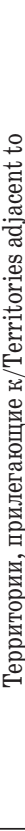 } & $\begin{array}{l}\text { Антипинскому } \\
\text { HПЗ } \\
\text { Antipinsky oil } \\
\text { refinery }\end{array}$ & $\begin{array}{l}\mathrm{Cr}_{1,9}>\mathrm{Na}_{1,1}>\mathrm{Hf}_{0,82}>\mathrm{Co}_{0,79}>\mathrm{Ca}_{0,67}>\mathrm{Ba}_{0,57}> \\
\mathrm{Ce}_{0,52}>\mathrm{Rb}_{0,51}>\mathrm{Eu}_{0,48}>\mathrm{Th}_{0,46}>\mathrm{Sb}_{0,44}>\mathrm{Sc}_{0,44}> \\
\mathrm{Tb}_{0,41}>\mathrm{U}_{0,41}>\mathrm{Lu}_{0,38}>\mathrm{Sm}_{0,38}>\mathrm{Ta}_{0,35}>\mathrm{Yb}_{0,33}> \\
\mathrm{Zn}_{0,3}>\mathrm{Cs}_{0,29}>\mathrm{Hg}_{0,28}>\mathrm{As}_{0,26}>\mathrm{Fe}_{0,24}>\mathrm{La}_{0,24}> \\
\mathrm{Nd}_{0,14}>\mathrm{Br}_{0,045}\end{array}$ & $\mathrm{Z}_{\mathrm{C}}=2$ \\
\hline & $\begin{array}{l}\text { Омскому НПЗ } \\
\text { Omsk oil } \\
\text { refinery }\end{array}$ & $\begin{array}{l}\mathrm{Cr}_{2,8}>\mathbf{C o}_{1,4}>\mathbf{N a}_{1,4}>\mathbf{Z n}_{1,4}>\mathbf{U}_{1,3}>\mathbf{C s}_{1,1}>\mathbf{R b}_{1,1}> \\
\mathrm{Sc}_{1,1}>\mathbf{C a}_{1,1}>\mathrm{Th}_{1,1}>\mathbf{C e}_{1}>\mathrm{As}_{0,92}>\mathrm{Hg}_{0,9}> \\
\mathrm{Lu}_{0,89}>\mathrm{Hf}_{0,89}>\mathrm{Tb}_{0,86}>\mathrm{Sb}_{0,84}>\mathrm{Eu}_{0,83}>\mathrm{Sm}_{0,82}> \\
\mathrm{Ba}_{0,75}>\mathrm{Yb}_{0,7}>\mathrm{Ta}_{0,65}>\mathrm{Fe}_{0,63}>\mathrm{La}_{0,55}>\mathrm{Br}_{0,55}> \\
\mathrm{Nd}_{0,55}>\mathrm{Sr}_{0,33}\end{array}$ & $\mathrm{Z}_{\mathrm{C}}=5$ \\
\hline & $\begin{array}{l}\text { Ачинскому } \\
\text { НПЗ } \\
\text { Achinsk oil } \\
\text { refinery }\end{array}$ & $\begin{array}{l}\mathrm{Co}_{2}>\mathrm{Cr}_{1,8}>\boldsymbol{U}_{1,7}>\boldsymbol{S c _ { 1 , 6 }}>\mathrm{Cs}_{1,5}>\mathrm{Zn}_{1,5}>\mathrm{Na}_{1,4}> \\
\mathrm{Rb}_{1,4}>\mathrm{Th}_{1,4}>\mathrm{Ce}_{1,3}>\mathrm{Tb}_{1,3}=\mathrm{Eu}_{1,3}>\mathrm{Ca}_{1,2}> \\
\mathrm{Lu}_{1,2}>\mathrm{As}_{1,2}>\mathrm{Sm}_{1,1}>\mathrm{Br}_{1}>\mathrm{Yb}_{0,97}>\mathrm{Ba}_{0,96}> \\
\mathrm{Fe}_{0,95}>\mathrm{Sb}_{0,93}>\mathrm{Ta}_{0,92}>\mathrm{Hf}_{0,9}>\mathrm{La}_{0,78}>\mathrm{Nd}_{0,7}> \\
\mathrm{Sr}_{0,48}>\mathrm{Hg}_{0,3}\end{array}$ & $\mathrm{Z}_{\mathrm{C}}=8$ \\
\hline & $\begin{array}{l}\text { Павлодарскому } \\
\text { НП3 } \\
\text { Pavlodar oil } \\
\text { refinery }\end{array}$ & 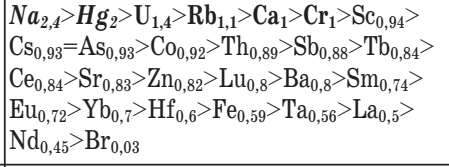 & $\mathrm{Z}_{\mathrm{C}}=4$ \\
\hline & $\begin{array}{l}\text { бывшему СИП } \\
\text { former STS }\end{array}$ & $\begin{array}{l}\mathrm{Au_{10 }}>\mathbf{Z n}_{3,4}>\mathbf{N a}_{2,5}>\boldsymbol{U}_{1,7}>\mathrm{Ca}_{1,5}>\mathbf{S c}_{1,4}>\mathbf{C o}_{1,3}> \\
\mathrm{Cr}_{1,3}>\mathrm{Lu}_{1,1}>\mathbf{S b}_{1,1}>\mathrm{Th}_{1,1}>\mathrm{Ce}_{1}>\mathrm{Rb}_{0,96}> \\
\mathrm{As}_{0,95}>\mathrm{Cs}_{0,93}>\mathrm{Sm}_{0,91}>\mathrm{Eu}_{0,9}>\mathrm{Ba}_{0,87}>\mathrm{Tb}_{0,86}> \\
\mathrm{Yb}_{0,83}>\mathrm{Fe}_{0,82}>\mathrm{Hf}_{0,74}>\mathrm{Sr}_{0,72}>\mathrm{Ta}_{0,7}>\mathrm{La}_{0,58}> \\
\mathrm{Nd}_{0,48}>\mathrm{Br}_{0,39}\end{array}$ & $\mathrm{Z}_{\mathrm{C}}=10$ \\
\hline & $\begin{array}{l}\text { ритория распо- } \\
\text { кения предприя- } \\
\text { I г. Tомска } \\
\text { ation of Tomsk }\end{array}$ & 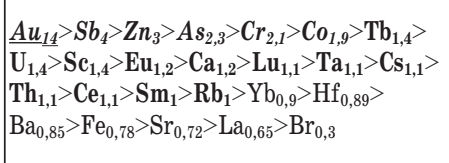 & $\mathrm{Z}_{\mathrm{C}}=2$ \\
\hline
\end{tabular}

Примечание: для 26 химических элементов для Антипинского НПЗ (Аu, Sr ниже предела обнаружения), для 27 хилических элелентов для Олского, Ачинского, Павлодарского НПЗ (Аи ниже предела обнаружения), для 27 химических элементов для бывшего СИП (не определена $\mathrm{Hg}$ ), для 25 химических элементов для 2. Томска (не определены $\mathrm{Na}, \mathrm{Nd} u \mathrm{Hg}, \mathrm{Sr}$ ниже предела обнаружения), жирным выделены хилические элеленты с коэффициентами кониентрации $\geq 1$, курсивом $\geq 1,5$, подчеркиванием $\geq 5$.

Note: for 26 chemical elements for the Antipinsky Oil Refinery ( $\mathrm{Au}, \mathrm{Sr}$ below the detection limit), for 27 chemical elements for the Omsk, Achinsky, Pavlodar Oil Refineries (Au below the detection limit), for 27 chemical elements for the former self-supporting insulator (not defined $\mathrm{Hg}$ ), for 25 chemical elements for the city of Tomsk ( $\mathrm{Na}, \mathrm{Nd}$ and $\mathrm{Hg}$, $\mathrm{Sr}$ are not defined below the detection limit), bold chemical ele ments with concentration coefficients $\geq 1$, italics $\geq 1.5$, underlining $\geq 5$.

Среди рассмотренных территорий район расположения Антипинского НПЗ характеризуется наименьшими количеством элементов с повышенными коэффициентами концентрации и суммарным показателем загрязнения, соответствующим фоновым условиям. К тому же в отличие от прочих изученных территорий здесь отсутствуют крайне высокие коэффициенты концентрации (все $<2$ ). Это, по нашему мнению, может быть связано с незначительным, по сравнению с другими предприятиями, временем функционирования данного производства. Для территории расположения Павлодарского НПЗ характерны повышенные коэффициенты концентрации для всех химических элементов, за исключением $\mathrm{Hf}$ и $\mathrm{Cr}$, и суммарный показатель загрязнения, соответствующий высокому уровню загрязнения. Для почв, прилегающих к Омскому НПЗ, характерны повышенные коэффициенты концентрации для всех изученных химических элементов и высокий уровень загрязнения. Территория расположения Ачинского НПЗ отличается наибольшим среди рассмотренных районов суммарным показателем загрязнения. Коэффициенты концентрации повышены для всех химических элементов, кроме $\mathrm{Cr}$. Почвы территории, прилегающей к бывшему СИП, также характеризуются высоким уровнем загрязнения. Коэффициенты

Таблица 4. Геохимический ряд и сумларный показатель загрязнения для верхнего горизонта почв территорий, подверженных воздействию факторов техногенеза, относительно условно-фоновой

Table 4. Geochemical series and the total pollution indicator for the upper soil horizon of territories subject to the influence of factors of technogenesis relative to conditionalbackground

\begin{tabular}{|c|c|c|c|}
\hline \multirow{5}{*}{ 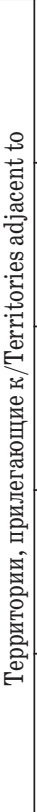 } & $\begin{array}{l}\text { Антипинскому } \\
\text { HПЗ } \\
\text { Antipinsky oil } \\
\text { refinery }\end{array}$ & 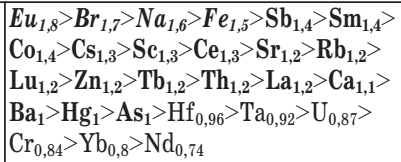 & $\mathrm{Z}_{\mathrm{C}}=7$ \\
\hline & $\begin{array}{l}\text { Oмскому НПЗ } \\
\text { Omsk oil refinery }\end{array}$ & 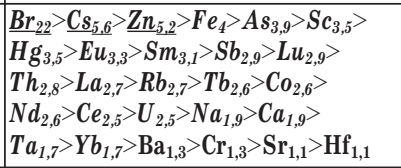 & $\mathrm{Z}_{\mathrm{C}}=67$ \\
\hline & $\begin{array}{l}\text { Ачинскому НПЗ } \\
\text { Achinsk oil } \\
\text { refinery }\end{array}$ & 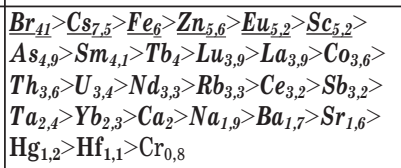 & $\mathrm{Z}_{\mathrm{C}}=104$ \\
\hline & $\begin{array}{l}\text { Павлодарскому } \\
\text { HПЗ } \\
\text { Pavlodar oil } \\
\text { refinery }\end{array}$ & 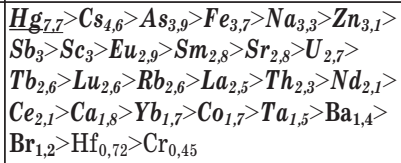 & $\mathrm{Z}_{\mathrm{C}}=46$ \\
\hline & $\begin{array}{l}\text { бывшему СИП } \\
\text { former STS }\end{array}$ & 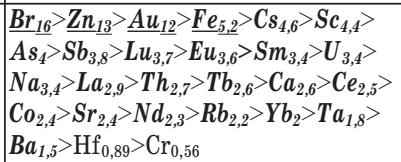 & $\mathrm{Z}_{\mathrm{C}}=84$ \\
\hline \multicolumn{2}{|c|}{$\begin{array}{l}\text { Территория } \\
\text { расположения пред- } \\
\text { приятий г. Томска } \\
\text { Location of Tomsk } \\
\text { enterprises }\end{array}$} & 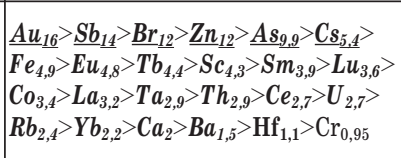 & $\mathrm{Z}_{\mathrm{C}}=99$ \\
\hline
\end{tabular}

Примечание: для 26 химических элементов для Антипинского НПЗ (Аu, Sr ниже предела обнаружения), для 27 химических элементов для Олского, Ачинского, Павлодарского НПЗ (Аи ниже предела обнаружения), для 27 химических элементов для бывще20 СИП (не определена $\mathrm{Hg}$ ), для 25 химических элементов для 2. Томска (не определены $\mathrm{Na}, \mathrm{Nd} u \mathrm{Hg}, \mathrm{Sr}$ ниже предела обнаружения), жирныл выделены хилические элементы с коэффициентами концентрации $\geq 1$, курсивом $\geq 1,5$, подчеркиванием $\geq 5$.

Note: for 26 chemical elements for the Antipinsky oil refinery ( $\mathrm{Au}, \mathrm{Sr}$ below the detection limit), for 27 chemical elements for the Omsk, Achinsky, Pavlodar oil refineries (Au below the detection limit), for 27 chemical elements for the former self-supporting insulator (not defined $\mathrm{Hg}$ ), for 25 chemical elements for the city of Tomsk ( $\mathrm{Na}, \mathrm{Nd}$ and $\mathrm{Hg}, \mathrm{Sr}$ are not defined below the detection limit), bold chemical elements with concentration coefficients $\geq 1$, italics $\geq$ ? 1,5, underlining $\geq 5$. 
$\mathrm{Na}$

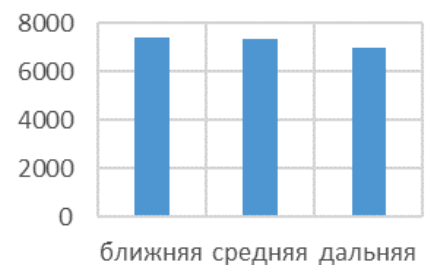

$\mathrm{Hf}$

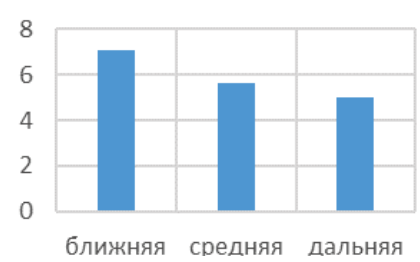

$\mathrm{U}$

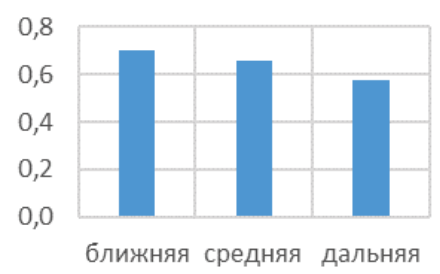

$\mathrm{Cr}$

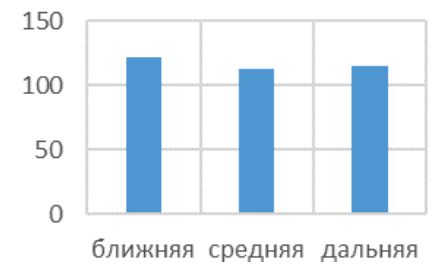

$\mathrm{Br}$

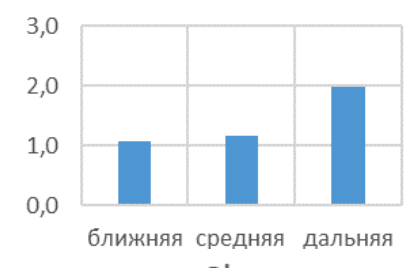

$\mathrm{Sb}$

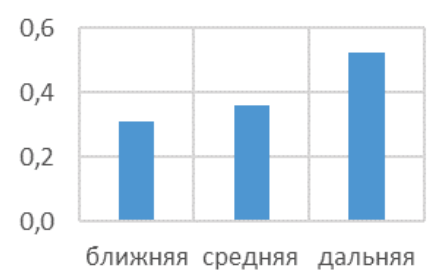

$\mathrm{Fe}$

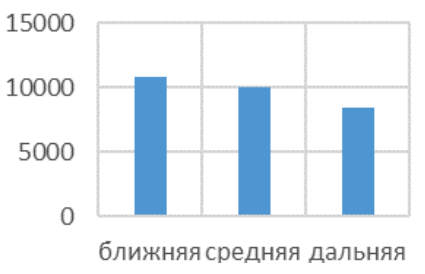

$\mathrm{Ta}$

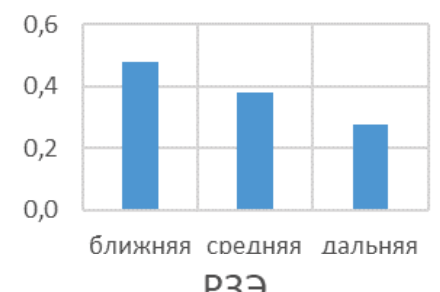

Р3Э

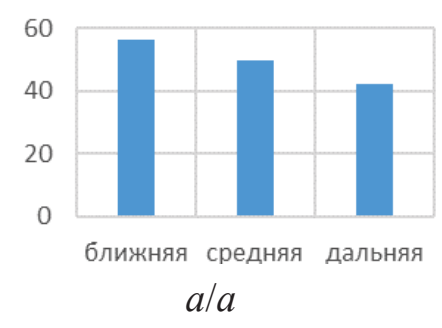

$\mathrm{Ba}$

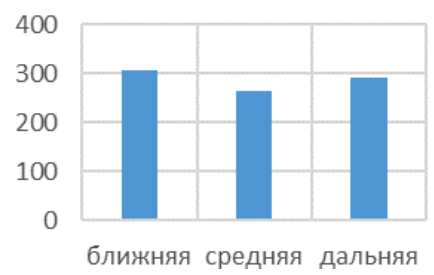

$\sigma / b$

$\mathrm{Sr}$

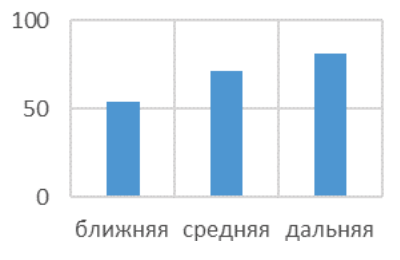

$\mathrm{Au}$

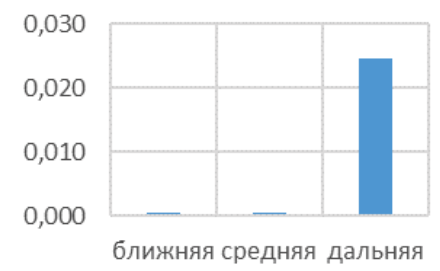

$B / c$
Cs

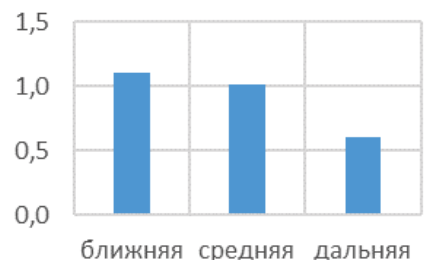

Th

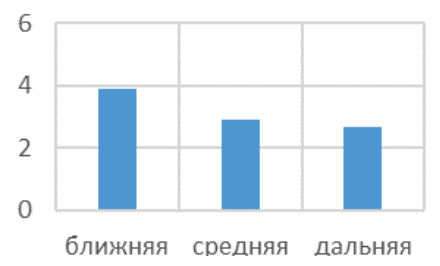

Co

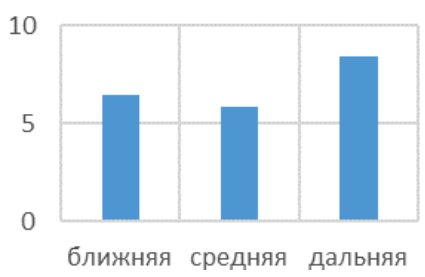

Zn

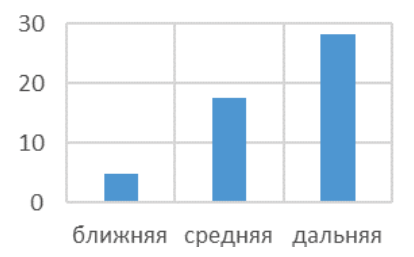

Рис. 1. Изменение содержания химических элементов в почвах с удалением от Антипинского НПЗ: а) с сокращением содержания с удалением от НПЗ; б) с наименьшим содержанием в средней зоне; в) с возрастанием содержания с удалением от НПз

Fig. 1. Changes in content of chemical elements in soils with distance from Antipinsky oil refinery: a) with reduction in the content with the distance from the refinery; $b$ ) with the lowest content in the middle zone; $c$ ) with increasing content with distance from the refinery 
концентрации не превышены только для $\mathrm{Hf}$ и $\mathrm{Cr}$. Почвы г. Томска характеризуются высоким уровнем загрязнения и повышенным содержанием всех рассмотренных элементов, кроме $\mathrm{Cr}$.

Если рассматривать полученные значения коэффициентов концентрации, можно отметить, что для всех территорий специфичным является концентрирование брома в 2 и более раз. Исключение составляет Павлодарский НПЗ, где коэффициент концентрации для этого элемента составляет 1,2 . При этом максимальные коэффициенты накопления отмечены нами для территорий расположения Омского (22) и Ачинского (41) комбинатов. Этот элемент способен формировать собственные локальные геохимические провинции на территориях деятельности как предприятий нефтепереработки и добычи, так и деятельности предприятий ядерно-топливного цикла [45]. Также для рассмотренных территорий, кроме зоны влияния Антипинского НПЗ, проявляется высокое накопление $\mathrm{Zn}$, особенно для бывшего СИП и г. Томска. В первом случае это определяется территориальной спецификой, что отражается в концентрировании данного элемента в комплексе сред. Во втором случае имеет значение специфичность данного элемента для урбанизированных и промышленных районов (металлургия, автомобильные шины и др.). Приоритетное накопление $\mathrm{Hg}$ в районе Павлодарского НПЗ может объясняться общей экологической ситуацией [46]

В целом для рассмотренных территорий, подверженных комплексному техногенному воздействию, характерно высокое содержание $\mathrm{Fe}, \mathrm{Cs}, \mathrm{Zn}$, $\mathrm{As}, \mathrm{Sc}, \mathrm{Sb}, \mathrm{Lu}, \mathrm{Eu}$. При этом для почв всех районов характерно невысокое накопление $\mathrm{Hf}$ и $\mathrm{Cr}$.

Такой широкий спектр элементов, интенсивно накапливающихся на изученных территориях, объясняется сложным комплексным характером, сложившимся в результате деятельности не только предприятий нефтепереработки, а, как правило, многопрофильным воздействием других объектов, функционирующих на урбанизированных территориях.

Кроме того, было проанализировано пространственное распределение химических элементов от техногенного объекта - Антипинского НПЗ, с учетом преобладающего ветра.

Без учета ветра выявлено накопление многих из изученных элементов в ближней к НПЗ зоне. Однако ряд элементов концентрируется в дальней зоне, что может объясняться их высокой летучестью (рис. 1).

При этом в обоих случаях для большинства элементов наблюдается последовательное изменение содержания с удалением от НПЗ. Тенденцию однозначного уменьшения по удаленности от объекта имеют натрий, железо, цезий, радиоактивные (торий и уран), редкоземельные и гафний с танталом. При этом стоит отметить, что, например, тенденция концентрирования в ближней зоне группы редкоземельных элементов является характерным признаком нефтеперерабатывающих предприятий, применяющих современные катализаторы [47].

По сторонам света для большинства химических элементов выявлено распределение, соответствующее розе ветров: преимущественное накопление в северном и восточном направлениях от НПЗ и минимальное в южном (рис. 2).

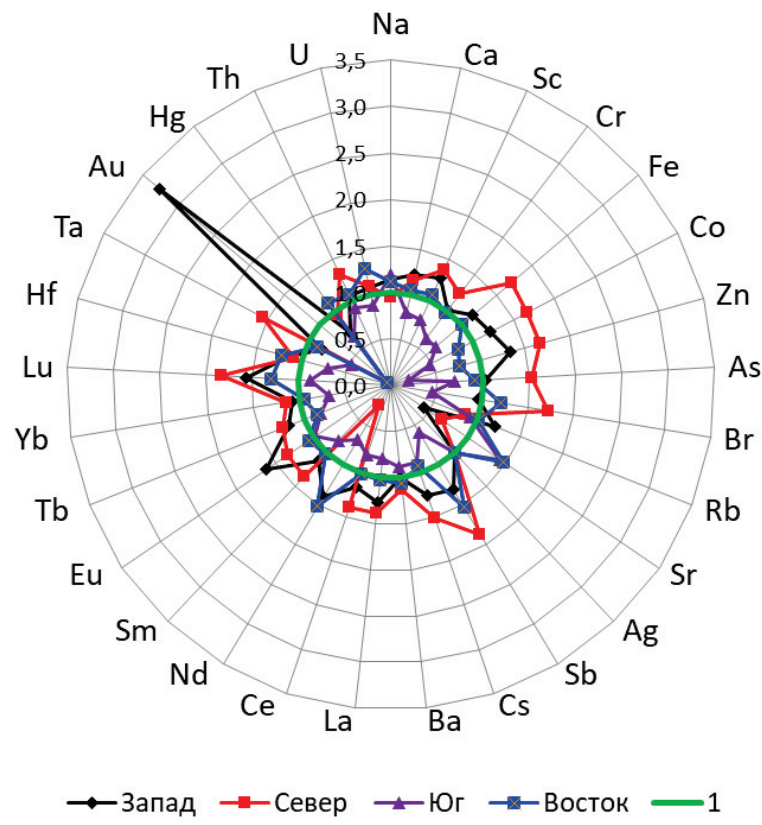

Pис. 2. Кониентрирование хилических элементов в верхнем го ризонте почв по направлениял сторон света относи тельно Антипинского НПЗ по сравнению со среднил по выборке

Fig. 2. Concentration of chemical elements in the upper horizon of the soils in the directions of the sides of the world relative to the Antipinsky oil refinery compared to the average for the sample

При этом для многих элементов отмечено весьма высокое накопление на западе, в частности для золота, что может объясняться переносом не только с территории завода, но и с территории города.

В целом специфика нефтеперерабатывающих предприятий определяется дополнительным привносом значительного количества химических элементов в верхнем горизонте почв, прилегающих к объектам. При этом для каждого предприятия характерен свой спектр химических элементов, специфика которого определяется как длительностью его существования, так и мощностью НПЗ, особенностями технологических схем, арматуры, проектных решений, техническим состоянием оборудования и коммуникаций, а также влиянием городов с их геоэкологическими проблемами. Эта специфика более ярко проявляется при анализе изменений содержаний по удалению от предприятия с учетом ветрового переноса.

Кроме того, как было отмечено, изученные территории находятся в различных регионах с разными естественными условиями, поэтому различия в 
элементном составе почв объясняются не только техногенным влиянием, но и природными факторами, прежде всего, минеральным и элементным составом почвообразующих пород и типом почв.

\section{Выводы}

1. Для каждой техногенной территории наблюдается специфический спектр химических элементов с повышенными содержаниями относительно фоновых территорий того же региона.

2. Почвы района расположения Антипинского

\section{СПИСОК ЛИТЕРАТУРЫ}

1. Ферсман А.Е. Геохимия. Т. 1. - Л.: Госхимтехиздат, Ленинград. отд-ние, 1933. - 328 с.

2. Ishchenko V., Vasylkivskyi I. Environmental pollution with heavy metals: case study of the household waste // Sustainable production: novel trends in energy, environment and material systems. - 2019. - V. 198. - P. 161-175.

3. X-Ray fluorescent method of heavy metals detection in soils of mining and chemical enterprises / V. Pohrebennyk, E. Dzhumelia, A. Mason, M. Cygnar // Proc. of $9^{\text {th }}$ International Conference on Developments in eSystems Engineering (DeSE). - Liverpool, 2017. - P. 323-328.

4. Technogenic pollution of soil due to mining and chemical enterprises / V. Pohrebennyk, E. Dzhumelia, 0. Korostynska, A. Mason, M. Cygnar // Proc. of $16^{\text {th }}$ International Multidisciplinary Scientific Geoconferences \& Expo SGEM. - Albena, 2016. V. II. - Iss. 5. - P. 363-370.

5. Toxic substances in hazardous household waste / V. Ishchenko, V. Pohrebennyk, B. Borowik, P. Falat, A. Shaikhanova // Proc. of International Multidisciplinary Scientific Geoconference SGEM. - Albena, 2018. - V. 18. - Iss. 4.2. - P. 223-230.

6. Assessment of batteries influence on living organisms by bioindication method / V. Ishchenko, V. Pohrebennyk, Y. Kozak, A. Kochanek, R. Politylo // Proc. of $16^{\text {th }}$ International Multidisciplinary Geoconference SGEM. - Albena, 2016. - V. II. Iss. 5. - P. 85-92.

7. Ishchenko V. Soil contamination by heavy metal mobile forms near landfill // Int. J. Environ. Waste Manage. - 2017. - № 20 (1). P. $66-74$.

8. Multispectral television monitoring of contamination of water objects by using macrophyte-based bioindication / R. Petruk, V. Pohrebennyk, S. Kvaternyuk, 0. Bondarchuk, M. Cygnar // $16^{\text {th }}$ International Multidisciplinary Scientific GeoConference SGEM. - Albena, 2016. - B. 5. - V. 2. - P. 597-602.

9. Pohrebennyk V., Petryk A. The degree of pollution with heavy metals of fallow soils in rural administrative units of Psary and Pìki in Poland // Proc. of $17^{\text {th }}$ International Multidisciplinary Scientific Geoconference SGEM. - Albena, 2017. - P. 967-974.

10. Ishchenko V., Llori J., Ramos C. Determinación del impacto ambiental de los componentes de champús sobre las algas Chlorella por el método de bioindicación // Waste Sci. Technol. - 2017. № $8(6)$. - P. 37-46.

11. Лобачева А.А. Влияние ОАО «Куйбышевский нефтеперерабатывающий завод” на почвенный и растительный покров прилегающих территорий: дис. ... канд. биол. наук. - Самара. 2010. -225 c.

12. Санация недр территории нефтеперерабатывающих заводов Д.Е. Быков, К.Л. Чертес, Е.Н. Петренко, О.В. Тупицына, В.Н. Пыстин, А.А. Подъячев // Экология и промышленность России. - 2019. - № 23 (3). - С. 9-13.

13. Tarafdar A., Sinha A. Public health risk assessment with bioaccessibility considerations for soil PAHs at oil refinery vicinity ar-
НПЗ характеризуются меньшим содержанием химических элементов в сравнении с почвами возле Павлодарского, Омского, Ачинского НПЗ, что объясняется отчасти значительно меньшим временем функционирования.

3. В пространственном распределении химических элементов относительно техногенного объекта наблюдается последовательное изменение содержания в зависимости от летучести по удалению и существенное влияние преобладающего ветра по сторонам света.

eas in India // Science of The Total Environment. - 2018. V. 616. - P. 1477-1484.

14. Alharbi B.H., Pasha M.J., Al-Shamsi M.A.S. Influence of different urban structures on metal contamination in two metropolitan cities. 2019. URL: https://doi.org/10.1038/ s41598-019-40180-x (дата обращения 15.09.2019).

15. Epstein A.C. The human health implications of oil and natural gas development // Environmental Issues Concerning Hydraulic Fracturing. - 2017. - V. 1. - P. 113-145.

16. Brockmeyer S., D'Angiulli A. How air pollution alters brain development: the role of neuroinflammation // Transl Neurosci. 2016. - № 7 (1). - P. 24-30.

17. Heavy metal pollution of oil-based drill cuttings at a shale gas drilling field in Chongqing, China: a human health risk assessment for the workers / T. Xu, L. Wang, X. Wang, T. Li, X. Zhan // Ecotoxicology and Environmental Safety. - 2018. - № 165 P. $160-163$.

18. Numerical analysis of frozen soil around the Mohe-Daqing crude oil pipeline with thermosyphons / L. Fang, B. Yu, J. Li, Y. Zhao, G. Yu, W. Zhao // Heat Transfer Engineering. - 2018. - V. 39. № 7-8, - P. 630-641.

19. Monitoring PAHs in the petrochemical area of Tarragona County, Spain: comparing passive air samplers with lichen transplants / N. Domínguez-Morueco, S. Augusto, L. Trabalón, E. Pocurull, F. Borrull, M. Schuhmacher, J.L. Domingo, M. Nadal // Environmental Science and Pollution Research. - 2017. - V. 24. № 13. - P. 11890-11900.

20. Determination of polycyclic aromatic hydrocarbons in ambient particulate matter PM2. 5 and 1-hydroxypyrene in children from an area near an oil refinery in Northeast Mexico / T. Montaño-Soto, L. Garza-Ocañas, C. Badillo-Castañeda, H. Garza-Ulloa // Human and Ecological Risk Assessment: an International Journal. 2017. - V. 23. - № 1. - P. 125-140.

21. Spatial analysis of volatile organic compounds in South Philadelphia using passive samplers / S. Mukerjee, L.A. Smith, E.D. Thoma, K.D. Oliver, D.A. Whitaker, T. Wu, M. Colon, L. Alston, T.A. Cousett, C. Stallings // Journal of the Air \& Waste Management Association. - 2016. - V. 66. - № 5. - P. 492-498.

22. Emission characteristics of volatile organic compounds and their secondary organic aerosol formation potentials from a petroleum refinery in Pearl River Delta, China / Z. Zhang, H. Wang, D. Chen, Q. Li, P. Thai, D. Gong, Y. Li, C. Zhang, Y. Gu, L. Zhou, L. Morawska, B. Wang // Science of The Total Environment. 2017. - V. 584. - P. 1162-1174.

23. A characterization of the soils and sediments in contaminated sites and rivers using petroleum biomarker compounds / N.-H. Kao, M.-C. Su, C.-C. Yen, Y.-J. Huang // Journal of Soils and Sediments - 2019. - № 19. - P. 241-254.

24. Jafarinejad S. Control and treatment of sulfur compounds specially sulfur oxides (SOx) emissions from the petroleum industry: a review // Chemistry International. - 2016. - V. 2. - № 4. P. 242-253. 
25. Jafarinejad S. Odours emission and control in the petroleum refinery: a review // Current Science Perspectives. - 2016. - V. 2 . № 3. - P. 78-82.

26. Monitoring coastal pollution associated with the largest oil refinery complex of Venezuela / A. Croquer, D. Bone, C. Bastidas, R. Ramos, E. García // 2016. URL: https://peerj.com/artic les/2171/ (дата обращения 15.09.2019).

27. Летувнинкас А.И. Антропогенные геохимические аномалии и природная среда. 2-е изд., доп. и испр. - Томск: Изд-во НТЛ, 2005. - 290 c

28. Абросимов А.А. Экология переработки углеводородных систем / под ред. д-ра хим. наук, проф. М.Ю. Доломатова, д-ра техн. наук, проф. Э.Г. Теляшева. - М.: Химия, 2002. - 608 с.

29. Язиков Е.Г. Экогеохимия урбанизированных территорий юга Западной Сибири: дис.... д-ра геол.-минерал. наук. - Томск, 2006. -423 c

30. Опекунова М.Г. Биоиндикация загрязнений. - СПб.: Изд-во С.-Петербургского университета, 2004. - 266 с.

31. Клос В.Р., Жовинский Э.Я. Биогеохимические индикаторы зон экологического риска городских агломераций // Пошукова та екологічна геохімія. - 2014. - № 1-2. - С. 14-15.

32. Методы изучения лесных сообществ / под ред. В.Т. Ярмишко, И.В. Лянгузовой. - СПб.: НИИХимии СПбГУ, 2002. - 240 с.

33. Охрана природы. Почвы. Общие требования к отбору проб: межгосударственный стандарт ГОСТ 17.4.3.01-2017: введен 01.01.19. - М.: Стандартинформ, 2018. - 4 с.

34. Розанов Б.Г. Морфология почв. - М.: Академический проект, 2004. -432 c

35. Фомин Г.С., Фомин А.Г. Почва. Контроль качества и экологической безопасности по международным стандартам. Справочник. - М.: Госстандарт России, 2001. - 300 c.

36. Полевой определитель почв / под ред. К.Т. Острикова. - М.: Почвенный ин-т им. В.В. Докучаева, 2008. - 182 с.

37. Геологическая карта Тюменской области (южные районы). Масштаб 1:2500000. URL: http://www.vsegei.ru/ru/info/gisatlas/ufo/tyumenskaya_obl/ (дата обращения 15.09.2019).

38. Судыко А.Ф. Определение урана, тория, скандия и некоторых редкоземельных элементов в двадцати четырех стандартных образцах сравнения инструментальным нейтронно-активационным методом // Радиоактивность и радиоактивные элементы в среде обитания человека: Материалы V Международной конференции. - Томск, 2016. - С. 620-624.

39. Ревич Б.А., Сает Ю.Е., Смирнова Р.С. Методические рекомендации по оценке степени загрязнения атмосферного воздуха населенных пунктов металлами по их содержанию в снежном покрове и почве (Утв. 15 мая 1990 г. № 5174-90). - М.: ИМГРЭ, 1990. - 16 с.

40. Алексеенко В.А., Алексеенко А.В. Химические элементы в геохимических системах. Кларки почв селитебных ландшафтов: монография. - Ростов н/Д: Изд-во Южного федерального университета, 2013. - 380 c.

41. Константинова Е.Ю. Валовые формы тяжелых металлов в поверхностном горизонте почв г. Тюмени // Проблемы геологии и освоения недр: Труды XXII Международного симпозиума им. академика М.А. Усова студентов и молодых ученых, посвященного 155-летию со дня рождения академика В.А. Обручева, 135-летию со дня рождения академика М.А. Усова, основателей Сибирской горно-геологической школы, и 110-летию первого выпуска горных инженеров в Сибири: в 2 т. - Томск, 2018. - C. 805-807.

42. Шигабаева Г.Н. Тяжелые металлы в почвах некоторых районов г. Тюмени // Вестник Тюменского государственного университета. Экология и природопользование. - 2015. - Т. 1. № 2. - C. 92-102.

43. Сибиркина А.Р. Биогеохимическая оценка содержания тяжелых металлов в сосновых борах Семипалатинского прииртышья: дис.... д-ра биол. наук. - Омск, 2014. - 496 с.

44. Ярошевский А.А. Кларки геосфер // Справочник по геохимическим поискам полезных ископаемых. - М.: Недра, 1990. C. $7-14$.

45. Бром в почвах Томской области / Т.А. Перминова, Н.В. Барановская, Б. Ларатт, Л.В. Жорняк, А.Ф. Судыко // Известия Томского политехнического университета. Инжиниринг георесурсов. - 2017. - Т. 328. - № 2. - С. 36-45.

46. Гельдымамедова Э.А. Тяжелые металлы в почвах и овощных культурах г. Павлодара республики Казахстан: автореф. дис. ... канд. биол. наук. - Новосибирск, 2007. - 141 с.

47. Шахова Т.С., Таловская А.В., Язиков Е.Г. Анализ поступления редкоземельных элементов из атмосферы на снежный покров в окрестностях Омского нефтеперерабатывающего завода / Снежный покров, атмосферные осадки, аэрозоли: климат и экология северных территорий и Байкальского региона: Материалы первой Всероссийской научно-практической конференции с международным участием, посвященной году экологии 2017 в России. - Иркутск, 2017. - С. 64-68.

Поступила 29.09.2019 г.

\section{Информация об авторах}

Боев В.B., аспирант отделения геологии Инженерной школы природных ресурсов Национального исследовательского Томского политехнического университета.

Барановская Н.В., доктор биологических наук, профессор отделения геологии Инженерной школы природных ресурсов Национального исследовательского Томского политехнического университета.

Боев B.A., кандидат биологических наук, доцент кафедры геоэкологии Тюменского государственного университета.

Джамбаев M.T., аспирант отделения геологии Инженерной школы природных ресурсов Национального исследовательского Томского политехнического университета; научный сотрудник Научно-исследовательского института радиационной медицины и экологии некоммерческого акционерного общества «Медицинский университет Семей».

Шахова T.C., кандидат геолого-минералогических наук, инженер отделения геологии Инженерной школы природных ресурсов Национального исследовательского Томского политехнического университета.

Жорняк Л.В., кандидат геолого-минералогических наук, доцент отделения геологии Инженерной школы природных ресурсов Национального исследовательского Томского политехнического университета. 


\section{CHANGE OF ELEMENTAL COMPOSITION OF SOIL UPPER HORIZON UNDER THE INFLUENCE OF OIL AND GAS REFINING ENTERPRISES}

Vladislav V. Boev',

v.-3@mail.ru

Natalya V. Baranovskaya',

natalya.baranovs@mail.ru

Viktor A. Boev²,

vikboev2009@mail.ru

\section{Merey T. Yambayevi,}

merei-semei@mail.ru

\section{Tatyana S. Shakhova',}

tatyanags29@yandex.ru

Lina V. Zhornyak',

zhornyak_lina@mail.ru

1 National Research Tomsk Polytechnic University,

30, Lenin avenue, Tomsk, 634050, Russia.

2 Tyumen State University,

6, Volodarsky street, Tyumen, 625003, Russia.

${ }^{3}$ Research Institute of Radiation Medicine and Ecology of Non-Profit Joint-Stock Company «Semey Medical University»,

258, Gagarin street, Semey, 071400, Kazakhstan.

The relevance of the research is caused by the lack of data on the effects of many refineries and other man-made objects on adjacent soils for specific regions when the general geochemical specificity of industrial sectors is studied.

The main aim of the research is to identify the specifics of the impact of the refineries and some other man-made objects on the soil by comparing the elemental composition with the data of conditionally background territory and the clarke.

Objects of research are soils of the Tyumen Federal Reserve and the territories of the location of Antipinsky, Omsk, Achinsk, Pavlodar refinery, soils of the settlements of Tomsk region and the city of Tomsk, soils of the territory affected by the former Semipalatinsk test site.

Methods: selection and preparation of test plots, selection and preparation of soils, determination of the elemental composition by instrumental neutron activation and atomic absorption methods, interpretation of results.

Results. The authors have investigated the elemental composition of the upper soil horizon of the eastern part of the Tyumen Federal Reserve, the location of the Antipinsky, Omsk, Achinsk, Pavlodar refineries, areas of the location of enterprises of the city of Tomsk, the zone of influence of the former Semipalatinsk test site. As a result of comparison with the data for regional soils, the geochemical specificity of each technogenic region was revealed. The paper reflects the difference in the elemental composition of the soils adjacent to different refineries, which is determined both by the technical parameters of the enterprises themselves and by the environmental conditions of the territories of their location. Comparing the clarke and conditionally background territory, the level of pollution and the range of chemical elements characterized by a high content were established for the named territories. Using the Antipinsky oil refinery as the example, the authors studied spatial distribution of elements by distance and the cardinal points from a man-made object.

\section{Key words:}

Soils elemental composition, Tyumen Federal Reserve, Antipinsky oil refinery,

technogenic impact on soils, Tomsk soils, Pavlodar oil refinery, Tomsk region soils,

Achinsk oil refinery, territory of influence of the former Semipalatinsk test site, Omsk oil refinery.

\section{REFERENCES}

1. Fersman A.E. Geokhimiya [Geochemistry]. Leningrad, Goskhimtekhizdat Publ., 1933. 328 p.

2. Ishchenko V., Vasylkivskyi I. Environmental pollution with heavy metals: case study of the household waste. Sustainable production: novel trends in energy, environment and material systems, 2020, vol. 198, pp. 161-175.

3. Pohrebennyk V., Dzhumelia E., Mason A., Cygnar M. X-Ray fluorescent method of heavy metals detection in soils of mining and chemical enterprises. Proc. of $9^{\text {th }}$ International Conference on De- velopments in eSystems Engineering (DeSE). Liverpool, 2017. pp. 323-328.

4. Pohrebennyk V., Dzhumelia E., Korostynska 0., Mason A., Cygnar M. Technogenic pollution of soil due to mining and chemical enterprises. Proc. of $16^{\text {th }}$ International Multidisciplinary Scientific Geoconferences \& Expo SGEM. Albena, 2016. Vol. II, Iss. 5, pp. 363-370.

5. Ishchenko V., Pohrebennyk V., Borowik B., Falat P., Shaikhanova A. Toxic substances in hazardous household waste. Proc. of International Multidisciplinary Scientific Geoconference SGEM. Albena, 2018. Vol. 18, Iss. 4.2, pp. 223-230. 
6. IshchenkoV., Pohrebennyk V., Kozak Y., Kochanek A., Politylo $R$. Assessment of batteries influence on living organisms by bioindication method. Proc. of $16^{\text {th }}$ International Multidisciplinary Geoconference SGEM. Albena, 2016. Vol. II, Iss. 5, pp. 85-92.

7. Ishchenko V. Soil contamination by heavy metal mobile forms near landfill. Int. J. Environ. Waste Manage, 2017, no. 20 (1), pp. 66-74.

8. Petruk R., Pohrebennyk V., Kvaternyuk S., Bondarchuk 0., Cygnar M. Multispectral television monitoring of contamination of water objects by using macrophyte-based bioindication. $16^{\text {th }}$ Inter national Multidisciplinary Scientific GeoConference SGEM. Albena, 2016. B. 5, vol. 2, pp. 597-602.

9. Pohrebennyk V., Petryk A. The degree of pollution with heavy metals of fallow soils in rural administrative units of Psary and Pìnki in Poland. Proc. of $17^{\text {th }}$ International Multidisciplinary Scientific Geoconference SGEM. Albena, 2017. pp. 967-974.

10. Ishchenko V., Llori J., Ramos C. Determinación del impacto ambiental de los componentes de champús sobre las algas Chlorella por el método de bioindicación [Determining the effect of Chlorella alga in shampoo on the environment by bioindication method]. Waste Sci. Technol., 2017, no. 8 (6), pp. 37-46. In Spain.

11. Lobacheva A.A. Vliyanie $O A O$ «Kuybyshevskiy neftepererabatyvayushchiy zavod» na pochvenny i rastitelny pokrov prilegayushchikh territoriy. Dis. Kand. nauk [The influence of Kuibyshev Refinery OJSC on soil and plant cover of the adjacent territories. Cand. Diss.]. Samara, 2010. 225 p.

12. Bykov D., Chertes K., Petrenko E., Tupitsyna 0., Pystin V., Pod'yachev A. Remediation of mineral resources polluted by oil refineries. Ecology and Industry of Russia, 2019, no. 23 (3), pp. $9-13$.

13. Tarafdar A., Sinha A. Public health risk assessment with bioaccessibility considerations for soil PAHs at oil refinery vicinity areas in India. Science of the Total Environment, 2018, vol. 616, pp. 1477-1484.

14. Alharbi B.H., Pasha M.J., Al-Shamsi M.A.S. Influence of Different Urban Structures on Metal Contamination in Two Metropolitan Cities. 2019. Available at: https://doi.org/10.1038/ s41598-019-40180-x (accessed 15 September 2019).

15. Epstein A.C. The human health implications of oil and natural gas development. Environmental Issues Concerning Hydraulic Fracturing, 2017, vol. 1, pp. 113-145.

16. Brockmeyer S., D'Angiulli A. How air pollution alters brain development: the role of neuroinflammation. Transl Neurosci, 2016, no. 7 (1), pp. 24-30.

17. Xu T., Wang L., Wang X., Li T., Zhan X. Heavy metal pollution of oil-based drill cuttings at a shale gas drilling field in Chongqing, China: a human health risk assessment for the workers. Ecotoxicology and Environmental Safety, 2018, no. 165, pp. $160-163$

18. Fang L., Yu B., Li J., Zhao Y., Yu G., Zhao W. Numerical analysis of frozen soil around the Mohe-Daqing crude oil pipeline with thermosyphons. Heat Transfer Engineering, 2018, vol. 39, № 7-8, pp. 630-641.

19. Domínguez-Morueco N., Augusto S., Trabalón L., Pocurull E., Borrull F., Schuhmacher M., Domingo J.L., Nadal M. Monitoring PAHs in the petrochemical area of Tarragona County, Spain: comparing passive air samplers with lichen transplants. Environmental Science and Pollution Research, 2017, vol. 24, no. 13, pp. 11890-11900.

20. Montaño-Soto T., Garza-Ocañas L., Badillo-Castañeda C., GarzaUlloa H. Determination of polycyclic aromatic hydrocarbons in ambient particulate matter PM2. 5 and 1-hydroxypyrene in children from an area near an oil refinery in Northeast Mexico. $\mathrm{Hu}$ man and Ecological Risk Assessment: an International Journal, 2017, vol. 23, no. 1, pp. 125-140

21. Mukerjee S., Smith L.A., Thoma E.D., Oliver K.D., Whitaker D.A., Wu T., Colon M., Alston L., Cousett T. A., Stallings C.
Spatial analysis of volatile organic compounds in South Philadelphia using passive samplers. Journal of the Air \& Waste Management Association, 2016, vol. 66, no. 5, pp. 492-498.

22. Zhang Z., Wang H., Chen D., Li Q., Thai P., Gong D., Li Y., Zhang C., Gu Y., Zhou L., Morawska L., Wang B. Emission characteristics of volatile organic compounds and their secondary organic aerosol formation potentials from a petroleum refinery in Pearl River Delta, China. Science of the Total Environment, 2017, vol. 584, pp. 1162-1174.

23. Kao N.-H., Su M.-C., Yen C.-C., Huang Y.-J. A characterization of the soils and sediments in contaminated sites and rivers using petroleum biomarker compounds. Journal of Soils and Sediments, 2019, no. 19, pp. 241-254.

24. Jafarinejad S. Control and treatment of sulfur compounds specially sulfur oxides ( $\mathrm{S} 0 \mathrm{x}$ ) emissions from the petroleum industry: a review. Chemistry International, 2016, vol. 2, no. 4, pp. 242-253.

25. Jafarinejad S. Odours emission and control in the petroleum refinery: a review. Current Science Perspectives, 2016, vol. 2, no. 3, pp. $78-82$.

26. Croquer A., Bone D., Bastidas C., Ramos R., García E. Monitoring coastal pollution associated with the largest oil refinery complex of Venezuela. 2016. Available at: https://peerj.com/articles/2171/ (accessed 15 September 2019).

27. Leturninkas A.I. Antropogennye geokhimicheskie anomalii i prirodnaya sreda [Anthropogenic geochemical anomalies and the natural environment]. Tomsk, NTL Publ., 2005. 290 p.

28. Abrosimov A.A. Ekologiya pererabotki uglevodorodnykh sistem [Ecology of processing hydrocarbon systems]. Moscow, Khimiya Publ., 2002. 608 p.

29. Yazikov E.G. Ekogeokhimiya urbanizirovannykh territoriy yuga Zapadnoy Sibiri. Dis. Dokt. nauk [Ecogeochemistry of urban territories in the south western Siberia. Dr. Diss.]. Tomsk, 2006. $423 \mathrm{p}$.

30. Opekunova M.G. Bioindikatsiya zagryazneniy [Bioindication of pollution]. St. Petersburg, S.-Petersburg University Publ., 2004. $266 \mathrm{p}$.

31. Klos V.R., Zhovinsky E. Ya. Biogeochemical indicators of ecological risk zones of urban agglomerations. Search and ecological geochemistry, 2014, no. 1-2, pp. 14-15. In Rus.

32. Metody izucheniya lesnykh soobshchestv [Methods for studying forest communities]. St. Petersburg, NIIXimii SPbGU Publ., $2002.240 \mathrm{p}$.

33. Okhrana prirody. Pochvy. Obshchie trebovaniya $k$ otboru prob: mezhgosudarstvenny standart GOST 17.4.3.01-2017. [Conservation of nature. Soils. General requirements for sampling: interstate SS 17.4.3.01-2017]. Moscow, Standartinform Publ., 2018. $4 \mathrm{p}$.

34. Rozanov B.G. Morfologiya pochv [Soil morphology]. Moscow, Akademichesky proekt Publ., 2004. 432 p.

35. Fomin G.S., Fomin A.G. Pochva. Kontrol kachestva i ekologicheskoy bezopasnosti po mezhdunarodnym standartam. Spravochnik [Soil. Quality control and environmental safety according to international standards. Directory]. Moscow, Gosstandart Rossii Publ., 2001. 300 p.

36. Polevoy opredelitel pochv [Field determinant of soil]. Moscow, Soil Institute named after V.V. Dokuchaev Publ., 2008. 182 p.

37. Geologicheskaya karta Tyumenskoy oblasti (yuzhnye rayony). Masshtab 1:2500000 [Geological map of the Tyumen region (southern areas). Scale 1:2500000]. Available at: http://www. vsegei.ru/ru/info/gisatlas/ufo/tyumenskaya_obl/ (accessed 15 September 2019).

38. Sudyko A.F. Opredelenie urana, toriya, skandiya i nekotorykh redkozemelnykh elementov v dvadtszati chetyrekh standartnykh obraztsakh sravneniya instrumentalnym neytronno-aktivatsionnym metodom [Determination of uranium, thorium, scandium and some rare-earth elements in twenty-four standard reference 
samples by the instrumental neutron activation method]. Radioaktiunost $i$ radioaktivnye elementy $v$ srede obitaniya cheloveka. Materialy V Mezhdunarodnoy konferentsii [Radioactivity and radioactive elements in the human environment. Proc. of the V International Conference]. Tomsk, 2016. pp. 620-624.

39. Revich B.A., Saet Yu.E., Smirnova R.S. Metodicheskie rekomen dacii po otsenke stepeni zagryazneniya atmosfernogo vozdukha naselennykh punktov metallami po ikh soderzhaniyu $v$ snezhnom pokrove i pochve (Utv. 15 maya 1990 g. № 5174-90) [Guidelines for assessing the degree of air pollution of populated areas by metals according to their content in snow cover and soil (Approved. May 15, 1990 no. 5174-90)] Moscow, IMGRE Publ., 1990. 16 p.

40. Alekseenko V.A., Alekseenko A.V. Khimicheskie elementy $v$ geokhimicheskikh sistemakh. Klarki pochv selitebnykh landshaftov: monografiya [Chemical elements in geochemical systems. Clarks of the soil of residential landscapes: a monograph]. Rostov on Don, Soth Federal University Publ., 2013. 380 p.

41. Konstantinova E.Yu. Valovye formy tyazhelykh metallov v poverkhnostnom gorizonte pochv $\mathrm{g}$. Tyumeni [Gross forms of heavy metals in the surface soil horizon of the city of Tyumen]. Problemy geologii i osvoeniya nedr. Trudy XXII Mezhdunarodnogo simpoziuma imeni akademika M.A. Usova studentov i molodykh uchenykh, posvyashchennogo 155-letiyu so dnya rozhdeniya akademika V.A. Obrucheva, 135-letiyu so dnya rozhdeniya akademika M.A.Usova, osnovateley Sibirskoy gorno-geologicheskoy shkoly, $i$ 110-letiyu pervogo vypuska gornykh inzhenerov v Sibiri [Problems of geology and subsoil development. Proc. of the XXII International Symposium named after academician M.A. Usov of students and young scientists dedicated to the $155^{\text {th }}$ anniversary of the birth of academician V.A. Obrucheva, the $135^{\text {th }}$ anniversary of the birth of academician M.A. Usov, the founders of the Siberian Mining and Geology School, and the $110^{\text {th }}$ anniversary of the first graduation of mining engineers in Siberia]. Tomsk, 2018. pp. 805-807.

42. Shigabaeva G.N. Heavy metals in the soils of some areas of the city of Tyumen. Bulletin of Tyumen State University. Ecology and nature management, 2015, vol. 1, no. 2, pp. 92-102. In Rus.
43. Sibirkina A.R. Biogeokhimicheskaya otsenka soderzhaniya tyazhelykh metallov $v$ sosnovykh borakh Semipalatinskogo priirtyshya. Dis. Dokt. nauk [Biogeochemical assessment of the content of heavy metals in the pine forests of the Semipalatinsk orirtshya. Drt. Diss. Abstract]. Omsk, 2014. 496 p.

44. Yaroshevskiy A.A. Klarki geosfer [Clarke of geosphere]. Spravochnik po geokhimicheskim poiskampoleznykh iskopaemykh [Reference book on geochemical prospecting of minerals]. Moscow, Nedra Publ., 1990. pp. 7-14.

45. Perminova T.A., Baranovskaya N.V., Laratte B., Zhornyak L.V., Sudyko A.F. Bromine in the soils of Tomsk region. Bulletin of the Tomsk Polytechnic University. Geo Assets Engineering, 2017, vol. 328 , no. 2, pp. 33-45. In Rus.

46. Geldymamedova E.A. Tyazhelye metally $v$ pochvakh $i$ ovoshchnykh kulturakh g. Pavlodara respubliki Kazakhstan. Avtoreferat Dis. Kand. nauk [Heavy metals in soils and vegetable crops in the city of Pavlodar, Republic of Kazakhstan. Cand. Diss. Abstract]. Novosibirsk, 2007. 141 p.

47. Shakhova T.S., Talovskaya A.V., Yazikov E.G. Analiz postupleniya redkozemelnykh elementov iz atmosfery na snezhny pokrov v okrestnostyakh Omskogo neftepererabatyvayushchego zavoda [Analysis of the entry of rare earth elements from the atmosphere to the snow cover in the vicinity of the Omsk refinery]. Snezhny pokrov, atmosfernye osadki, aerozoli: klimat i ekologiya severnykh territoriy i Baykalskogo regiona. Materialy pervoy Vserossiyskoy nauchno-prakticheskoy konferentsii s mezhdunarodnym uchastiem, posvyashchennaya Godu ekologii $2017 v$ Rossii [Snow cover, precipitation, aerosols: climate and ecology of the northern territories and the Baikal region. Proc. of the first AllRussian scientific-practical conference with international participation, dedicated to the Year of Ecology 2017 in Russia]. Irkutsk, 2017. pp. 64-68.

Received: 29 September 2019.

\section{Information about the authors}

Vladislav V. Boev, graduate student, National Research Tomsk Polytechnic University.

Natalia V. Baranovskaya, Dr. Sc., professor, National Research Tomsk Polytechnic University.

Viktor A. Boev, Cand. Sc., associate professor, Tyumen State University.

Merey T. Yambayev, graduate student, National Research Tomsk Polytechnic University; researcher, Research Institute of Radiation Medicine and Ecology of Non-Profit Joint-Stock Company «Semey Medical University».

Tatyana S. Shakhova, engineer, National Research Tomsk Polytechnic University.

Lina V. Zhornyak, Cand. Sc., associate professor, National Research Tomsk Polytechnic University. 